\title{
Assessing the effect of mergers and acquisitions on revenue efficiency: evidence from Malaysian banking sector
}

\begin{abstract}
The article attempts to examine the effect of mergers and acquisitions (M\&As) on Malaysian banks' revenue efficiency. The data gathered in this study are divided into two event windows: the pre-merger (1995-1996) and post-merger (2002-2009) periods. The sample selected for this study comprised 34 commercial banks, including the control group of banks. We employ the Data Envelopment Analysis (DEA) method to measure the efficiency of Malaysian banks during both the pre- and post-merger periods. The results indicate that the Malaysian banks' revenue efficiency has not significantly improved during the post-merger compared to the pre-merger period.
\end{abstract}

Keyword: Bank; Mergers and acquisitions; Data envelopment analysis; revenue efficiency 